\title{
O consentimento livre e esclarecido: do código de Nuremberg às normas brasileiras vigentes
}

\author{
Rafael Jadoski ${ }^{a}$, Sofia Rech Mostardeiro ${ }^{\mathrm{a}}$, Júlia d`Avila Exterkoetter ${ }^{\mathrm{a}}$, Nelson Grisard ${ }^{\mathrm{a}}$, \\ Alexandre Ademar Hoeller ${ }^{*}$,b

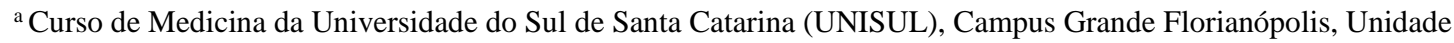 \\ Pedra Branca, Palhoça, Santa Catarina, Brasil; \\ ${ }^{\text {b }}$ Programa de Pós-Graduação em Ciências Médicas, Departamento de Clínica Médica, Laboratório de Ciências \\ Médicas, Universidade Federal de Santa Catarina (UFSC), Florianópolis, Santa Catarina, Brasil.
}

\section{Histórico do Artigo \\ Recebido em: 21/07/2017 \\ Aceito em: 17/10/2017 \\ Palavras-chave: \\ códigos de ética \\ consentimento livre e \\ esclarecido \\ autonomia pessoal autonomia profissional \\ Nuremberg \\ Declaração de Helsinque \\ Convenção de Genebra}

\section{Keywords:}

ethical code

informed consent

personal autonomy

professional autonomy

Nuremberg

Declaration of Helsinki

Geneva Convention

\begin{abstract}
RESUMO
O presente trabalho tem por objetivo demonstrar a evolução do conceito de consentimento livre e esclarecido através da história, desde a necessidade da criação do código de Nuremberg, passando pela declaração de Genebra, declaração de Helsinque e suas atualizações, até a atual legislação brasileira que incorporou estas diretrizes. O trabalho traz os principais artigos e parágrafos destes códigos, fazendo referência à especificidade necessária na forma de escrever e descrever a obrigatoriedade e a extensão do conceito de consentimento do paciente, para que não fiquem dúvidas na interpretação do direito que deve ser assegurado ao ser humano, no que diz respeito a sua autonomia, segurança e tratamento. Assim, ressaltamos a necessidade de levarmos a termo o princípio hipocrático de primum non nocere (em primeiro lugar, não fazer o mal), um eterno paradigma ético e moral enfrentado cotidianamente durante o ato médico.
\end{abstract}

The informed consent: from the Nuremberg Code to the current Brazilian norms

\begin{abstract}
This study aimed to demonstrate the evolution of the concept of informed consent throughout history, from the need of creation of the Nuremberg code, the Geneva Declaration, the Helsinki Declaration up to the current Brazilian legislation. Herein, we present the main articles and paragraphs of these codes, referring to the specificity required in the writing format and describing the obligation and the extension of the concept of patient consent. Thus, the misunderstanding or misinterpretation of the rights which must be guaranteed to the patients, regarding their autonomy, security and treatment. In this sense, we emphasize the need to highlight the Hippocratic Oath of the primum non nocere (first do no harm), an eternal ethical and moral paradigm faced daily during the medical act.
\end{abstract}

\section{Introdução}

A linha temporal da história, desde os primórdios até a contemporaneidade, é marcada pela luta da humanização do tratamento médico. Inicialmente, a autonomia do ser humano estava relegada a um segundo plano na relação médico-paciente, priorizando o caráter paternalista - denominado modelo sacerdotal de relação - em que cabia ao médico a tomada de decisões, sendo ele o detentor de maior poder na relação (1). Tal supremacia pôde contribuir e abrir espaço para a desumanização da conduta médica. Nesse contexto, destacaram-se, no último século, os experimentos conduzidos durante a Segunda Guerra Mundial (1936-45), realizados de maneira forçosa, ignorando a autonomia, o consentimento e o bem-estar dos indivíduos submetidos às pesquisas e às

\footnotetext{
*Autor Correspondente: alexandrehoeller@gmail.com (A. A. Hoeller)
} 
mais diversas barbáries (2).

Nesse ínterim, a criação de novos códigos éticos veio à tona, principalmente no contexto pós-guerra, quando se notou a necessidade do estabelecimento de normas que possam guiar a atuação do médico em relação ao paciente, buscando respeitar os princípios da beneficência, não maleficência e, principalmente, da autonomia deste (3). Como consequência das barbáries médicas cometidas durante a guerra, veio à tona os preceitos do Juramento de Hipócrates (século V a.C.) e a necessidade de revisão da conduta médica, resultando, posteriormente, na Declaração de Genebra (1948), mais atualizada e condizente com a realidade atual. Dessa forma, as obrigações do médico foram amplamente debatidas e estudadas, culminando em diretrizes e leis para a prática da sua profissão (4).

Assim, o presente trabalho tem por objetivo traçar um panorama da evolução conceitual do consentimento livre e esclarecido de pacientes, analisando códigos de ética que marcaram a conduta médica ao longo da história. Busca-se demonstrar as modificações de artigos e parágrafos tocantes ao consentimento esclarecido, desde o Código de Nuremberg até a visão jurídica brasileira através do tempo. Em um momento em que a judicialização da medicina se torna latente, analisar e compreender as condutas antigas e novos entendimentos na comunicação com o paciente - quanto à sua participação em eventos terapêuticos ou de pesquisa - mostram-se não só importantes no ato médico, mas imprescindíveis para que o ser humano esteja resguardado em seus direitos fundamentais.

\section{Material e Métodos}

Esta revisão narrativa foi formulada a partir da seleção de artigos científicos que denotam a criação, a discussão e a evolução de normas éticas vinculadas à autonomia de pacientes submetidos a testes experimentais e/ou clínicos estabelecidos, obtidos nos bancos de dados PubMed, Scielo e Google Acadêmico, empregando as seguintes palavras-chave: ethical code, informed consent, bioethics, medical conduct, health legislation, autonomy, Nuremberg, Geneva e Helsinki. Artigos publicados em outros idiomas, excetuando a linha inglesa ou portuguesa, não foram incluídos no presente trabalho.

\section{Resultados e Discussão}

\subsection{O Princípio: Código de Nuremberg}

Entre os anos de 1945 e 1949, após o término da Segunda Guerra Mundial, iniciou-se o julgamento dos ex-líderes do regime nazista, sob a acusação de crime de guerra, por um Tribunal Militar Internacional, mais tarde reconhecido como o Julgamento de Nuremberg. Vinte e três médicos e colaboradores foram julgados, processo que fícou posteriormente conhecido como "O julgamento dos doutores". Como veredicto, foram estabelecidos dez pontos de diretrizes para a condução de experimentos em humanos. Surge, assim, o Código de Nuremberg, considerado um dos responsáveis por regulamentar a experimentação científica e defender a beneficência em prol de seres humanos envolvidos em pesquisas $(2,5)$.

É importante notar que evidências históricas apontam a defesa de preceitos éticos há mais de 2000 anos antes de Cristo, como observado no Código de Hamurabi, documento no qual é estabelecido punição a doutores que causam o mal a seus pacientes durante o exercício terapêutico (6). Posteriormente, por volta do ano 400 antes de 
Cristo, discípulos de Hipócrates estabeleceram uma série de regras comportamentais para a conduta médica, formando a base do Juramento Hipocrático (baseado no preceito primum non nocere, em tradução livre, "em primeiro lugar, não causar o mal"), considerado um paradigma da ética profissional e da responsabilidade moral (7). Nesse ínterim, até a era moderna, muitas normas e códigos foram criados, destacando-se as contribuições do médico Thomas Percival, com a publicação do Código de Ética Médica e Preceitos Adaptados para a Conduta Profissional de Médicos e Cirurgiões, em 1803. O código redigido por Percival tornou-se um verdadeiro manual da ética médica e conduta, baseado na independência e autoridade moral dos médicos e no cuidado e respeito ao seus pacientes (8).

A despeito da preocupação milenar em se estabelecer condutas apropriadas no cuidado médico, inúmeros episódios de conduta inapropriada afloraram na história recente. Em 1900, com intuito de proteger mulheres contra sífilis, o médico alemão Albert Neisser inoculou o vírus em prostitutas sem qualquer orientação ou consentimento delas. A vacina hipotética de Neisser não surtiu efeito e muitas dessas mulheres acabaram acometidas pela doença, originando o conhecido "escândalo de Neisser". A partir desse episódio, a obtenção de consentimento livre e esclarecido foi requerida previamente a qualquer experimentação ou tratamento (9), sendo considerado, desde então, um pilar na proteção dos direitos de pacientes (2). Posteriormente, na década de 30, o governo da Prússia publicou o Guia para Novas Terapias e Experimentação em Humanos, referindo-se aos princípios da beneficência, não-maleficência, autonomia do paciente e a doutrina do consentimento livre e esclarecido, recomendando fortemente a proibição da experimentação em pessoas convalescentes e economicamente ou socialmente destituídas (9). No mesmo período, na própria Alemanha, experimentos conduzidos, sem consentimento, com a vacina BCG, provocaram a morte de 75 das 100 crianças testadas, episódio conhecido como o "desastre de Lübeck" (10). Em pouco tempo, sob influência da ideologia nazista, a "ciência racial" ganhou espaço, dando início a uma onda de extermínio generalizado. A medicina, então, abraça a eugenia, o movimento de higiene social e o antissemitismo $(2,11)$.

Apesar da preocupação histórica em estabelecer preceitos éticos, os primeiros códigos com ênfase específica na ética médica surgiram com o fim da Segunda Guerra Mundial e o julgamento das atrocidades cometidas pelo regime nazista, originando o Código de Nuremberg (1947) e, posteriormente, destacando-se a Declaração de Genebra (1948), o Código Internacional de Ética Médica (1949) e Declaração de Helsinque (1964). Importante, a grande contribuição do Código de Nuremberg consiste na sobreposição da ética hipocrática e a proteção aos direitos humanos em um único código (12), exigindo que clínicos e pesquisadores protejam os interesses dos seus pacientes, mas que também estes participem ativamente da sua própria proteção e tenham autonomia através do consentimento livre e esclarecido, ao direito à desistência (Comissão Nacional para a Proteção de Seres Humanos da Pesquisa Biomédica e Comportamental, 1978).

\subsection{Evolução dos conceitos éticos}

A seguir, são analisados os itens específicos referentes ao consentimento livre e esclarecido, desde seu aparecimento no Código de Nuremberg, passando pela Declaração de Helsinque e suas atualizações:

1947 - Código de Nuremberg 
Quadro 1 - O Código de Nuremberg (12)

\begin{tabular}{|c|}
\hline 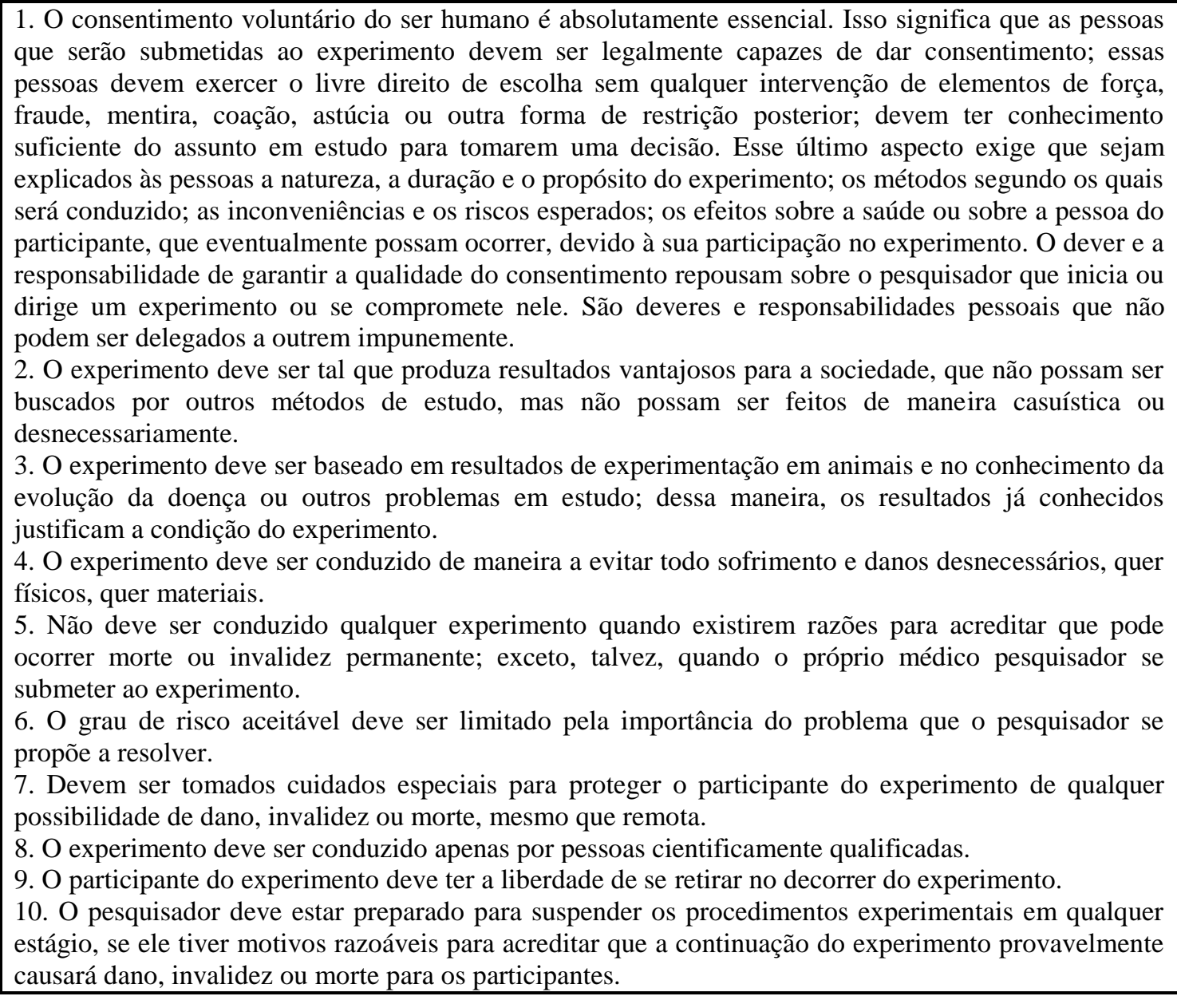 \\
\hline
\end{tabular}

Embora o Código de Nuremberg não tenha sido prontamente adotado como norma legal por nenhum país ou associação médica, os seus 3 elementos básicos (consentimento voluntário e informado, análise favorável de risco-benefício e o direito de desistência sem repercussão) influenciaram a área dos direitos humanos e da bioética, sendo estes critérios aceitos em todo o mundo e consagrados em inúmeras leis internacionais, além de constituírem a base do Guia de Ética Internacional para Pesquisa Biomédica Envolvendo Seres Humanos, publicado em 1982 (5, 13). Inclusive, a necessidade do consentimento livre e esclarecido mencionada no Código, é hoje vista como necessidade ética não apenas na pesquisa, como também para o tratamento médico.

\section{8 - Declaração de Genebra}

Quadro 2 - Fragmento da Declaração de Genebra (14)

EU JURO SOLENEMENTE consagrar a minha vida a serviço da humanidade;

EU PRATICAREI a minha profissão com consciência e dignidade;

EU NÃO USAREI meu conhecimento médico para violar direitos humanos e liberdades civis, mesmo sob ameaça

Anteriormente à Declaração de Helsinque e do código de Nuremberg, a conduta médica era orientada exclusivamente pela tradição Hipocrática, tornando-se mais moderna a partir da Declaração de Genebra, em 1948 (14), e passando a ser o escopo do juramento dos novos médicos no momento de sua formatura. Importante ressaltar não 
há neste uma referência explícita ao consentimento esclarecido do paciente, mas sim à nobreza do respeito à vida humana, à não contrariedade das leis da humanidade e à dignidade e consciência do profissional.

\section{4 - Declaração de Helsinque}

Adotada pela $18^{\mathrm{a}}$ Assembleia Geral da WMA, Helsinque, Finlândia, junho de 1964 e alterada pela 29a Assembléia Geral da WMA, Tóquio, Japão, outubro de 1975.

$35^{\text {a }}$ Assembléia Geral da WMA, Veneza, Itália, outubro de 1983.

41 ${ }^{\text {a }}$ Assembléia Geral da WMA, Hong Kong, setembro de 1989.

$48^{\mathrm{a}}$ Assembléia Geral da WMA, Somerset West, República da África do Sul, outubro de 1996

$52^{\mathrm{a}}$ Assembleia, em Edimburgo, na Escócia, em outubro de 2000

$59^{\text {a }}$ Assembleia, em Seul, Coreia do Sul, em outubro de 2008

$64^{\text {a }}$ Assembleia, em Fortaleza, Brasil, em outubro de 2013

Versão de 2013 (15):

Quadro 3 - Fragmento da Declaração de Helsinque

25. A participação de pessoas capazes de dar consentimento informado para serem participantes sujeitos de investigação médica tem de ser voluntária. Embora possa ser apropriado consultar membros da família ou líderes comunitários, nenhuma pessoa capaz deve ser selecionada para um projeto de investigação sem que livremente o aceite.

26. Na investigação médica em seres humanos capazes de consentir, cada potencial sujeito tem de ser informado adequadamente das finalidades, métodos, fontes de financiamento e possíveis conflitos de interesse, ligações institucionais do investigador, benefícios expectáveis, potenciais riscos do estudo e incómodos que lhe possam estar associados, ajudas após o estudo, bem como outros aspetos relevantes do estudo. O potencial participante tem de ser informado do direito a recusar-se a participar no estudo ou de, em qualquer altura, revogar o consentimento de participar sem represálias. Deve ser dada atenção especial às exigências específicas de informação de certos potenciais participantes assim como aos métodos usados para prestar a informação.

Após assegurar-se de que o potencial participante compreendeu a informação, o médico ou outro profissional qualificado deve então obter o consentimento livre e informado do potencial participante, preferencialmente por escrito. Se o consentimento não pode ser feito por escrito, o consentimento verbal tem de ser formalmente documentado e testemunhado. Deve ser dada a todos os participantes em investigações médicas a opção de serem informados dos efeitos gerais e resultados do estudo.

27. Quando pede o consentimento informado para a participação num projeto de investigação, o médico deve ser particularmente cauteloso se o potencial participante tem uma relação de dependência consigo ou possa consentir sob coação. Em tais situações o consentimento informado deve ser pedido por pessoa adequadamente qualificada que seja completamente independente dessa relação.

28. Para o caso de um potencial participante na investigação ser incapaz de decidir, o médico tem de pedir o consentimento informado ao seu representante legal. Estas pessoas não devem ser incluídas num projeto de investigação que não ofereça a probabilidade de os beneficiar, salvo se houver a intenção de promover a saúde da população representada pelo potencial participante, se a investigação não puder, em alternativa, ser feita com participantes sujeitos capazes de decidir e se a investigação implicar apenas risco mínimo e incómodo mínimo.

29. Quando se trate de um potencial participante na investigação considerado incapaz para decidir mas que pode dar assentimento a decisões acerca da sua participação na investigação, o médico deve procurar esse assentimento em acréscimo ao consentimento do representante legal. $\mathrm{O}$ dissentimento do potencial participante deve ser respeitado.

30. A investigação envolvendo sujeitos que são incapazes física ou mentalmente de dar consentimento, por exemplo, doentes inconscientes, apenas pode ser feita se a condição física ou mental que os impede de dar o consentimento informado for uma característica necessária da população investigada. Em tais circunstâncias, o médico deve obter o consentimento informado do representante legal. Se tal representante não está disponível e se a investigação não pode ser adiada, o estudo pode prosseguir sem consentimento informado desde que as razões específicas para incluir sujeitos com uma condição que 
os impede de dar consentimento estejam expressas no protocolo de investigação e o estudo tenha sido aprovado por uma comissão de ética para a investigação. O consentimento para permanecer na investigação deve ser obtido logo que possível do sujeito ou do seu representante legal.

31. O médico tem de informar inteiramente o doente sobre quais os aspetos da assistência que estão relacionados com a investigação. A recusa de um doente em participar no estudo ou a decisão de um doente interromper a sua participação no estudo nunca pode interferir com a relação médico-doente.

32. Para a investigação médica que usa dados e material humano identificáveis, como investigação com material e dados de biobancos ou repositórios similares, os médicos têm de procurar obter o consentimento para a sua recolha, guarda e/ou reutilização. Pode haver situações excecionais em que o consentimento seja impossível de obter ou inexequível para a investigação em apreço ou ponha em causa a validade da mesma. Em tais situações a investigação apenas pode ser feita após apreciação e aprovação por uma comissão de ética para a investigação.

Entretanto, o princípio do consentimento de forma completa e totalmente esclarecido nem sempre é respeitado, mesmo na atualidade. Isso é percebido, por exemplo, no caso da experiência farmacológica de 1996, na Nigéria, durante uma epidemia de meningite. Doses do antibiótico Trovan ${ }^{\circledR}$ (trovafloxacina) foram aplicadas em crianças de famílias vulneráveis e, mais tarde, comprovou-se que a empresa não respeitara os protocolos de consentimento, nem passara por um comitê de ética $(16,17)$. Outro caso de destaque foi a remoção, retenção e manutenção de órgãos infantis em hospitais britânicos, principalmente em Alder Hey, sem que os doadores estivessem informados sobre os procedimentos e seus potenciais riscos (18). Há também discussões de casos nos Estados Unidos, como a morte de um paciente em um ensaio de terapia genética, ou, ainda, a morte de um voluntário saudável que participou de um projeto envolvendo a inalação de um composto químico como parte de um estudo de asma (19). Tais exemplos comprovam a ainda persistente falta de ciência completa dos participantes em relação aos riscos inerentes em um projeto de pesquisa ou em procedimentos médicos, além de evidenciar violações do processo de consentimento livre e esclarecido. As respostas da sociedade a tais casos devem ser no sentido de existir constante vigilância sobre os estudos clínicos e na informação prévia dada ao paciente, em relação aos procedimentos clínicos. $\mathrm{O}$ resultado esperado à maior e mais efetiva implementação e às revisões do consentimento livre e esclarecido para uma proteção abrangente aos direitos e ao bem-estar dos indivíduos, oferecendo-lhes a oportunidade de fazer escolhas conscientes e informadas (20).

\subsection{Histórico da legislação brasileira}

\section{5 - Código de Ética Médica (21)}

Quadro 4 - Fragmento do Código de Ética Médica.

Art 31. O médico tem o dever de informar o doente quanto ao diagnóstico, prognóstico e objetivos do tratamento, salvo se as informações puderem causar-lhe dano, devendo ele neste caso, prestá-las à família ou aos responsáveis

Apenas no ano de 1975, o Conselho Federal de Medicina adere oficialmente à Declaração de Helsinque (22). A partir da década seguinte, são elaborados documentos específicos a respeito do tema. Em 1981, através de uma portaria, a Divisão de Vigilância Sanitária de Medicamentos do Ministério da Saúde (DIMED) instituiu a necessidade de um Termo de Reconhecimento de Risco para todo projeto de pesquisa feito com drogas que ainda não houvessem sido registradas. O Conselho Federal de Medicina estabeleceu, em 1982, a obrigatoriedade da obtenção do consentimento do 
paciente para a realização de procedimentos necessários para o diagnóstico e terapias (23).

\section{4 - Código Brasileiro de Deontologia Médica (24)}

Quadro 5 - Fragmento do Código Brasileiro de Deontologia Médica.

Art 23. Exagerar a gravidade do diagnóstico ou prognóstico, complicar a terapêutica ou exceder-se no número de visitas ou consultas.

Art 24. Efetuar, salvo diante de urgência ou emergência, qualquer ato médico sem o consentimento prévio do paciente ou de seu responsável.

Art 25. Deixar de informar o paciente, sua família ou responsável do diagnóstico terapêutico, prognóstico e objetivos do tratamento, salvo quando a comunicação possa provocar danos ao paciente.

Art 26. Exercer sua autoridade de maneira a limitar os direitos do paciente de decidir sobre sua pessoa e seu bem-estar.

Art 27. Assumir a responsabilidade do tratamento de doença grave ou toxicomania de pessoa de sua família ou que viva sob sua dependência, salvo se na localidade não houver outro médico.

Art 31. Empregar ou usar experimentalmente qualquer tipo de terapêutica ainda não liberada para o uso no País, sem a devida autorização dos órgãos competentes, do consentimento do paciente ou de seu responsável, devidamente informado da situação e das possíveis consequências.

Nos Códigos de Ética Médica subsequentes - examinadas neste ensaio as versões de 1984 e 1988 - é possível observar maior destaque, para a importância do consentimento livre e esclarecido na prática médica, estando o princípio em cerca de dez artigos ao longo do código. Diferentemente de regulamentações anteriores, as quais não traziam tantos pormenores, os manuais do final da década de 80 abordam aspectos como: uso da autoridade científica e moral do médico para influenciar o paciente em sua decisão; informação a respeito não só do diagnóstico e da terapia, mas também do prognóstico e todos os riscos envolvidos na doença e nos procedimentos a serem realizados; respeito à escolha do paciente sobre métodos contraceptivos; informação ao paciente ou representante legal em casos de transplante de órgãos; uso de terapias não liberadas sem o consentimento do paciente; pesquisas médicas em comunidades sem o conhecimento dessas; além da informação da natureza e consequência de pesquisas individualizadas $(24,25)$.

\section{0 - Código de Ética Médica (26)}

Quadro 6 - Fragmento do Código de Ética Médica.

Art 12. Deixar de esclarecer o trabalhador sobre as condições de trabalho que ponham em risco sua saúde, devendo comunicar o fato aos empregadores responsáveis.

Parágrafo único. Se o fato persistir, é dever do médico comunicar o ocorrido às autoridades competentes e ao Conselho Regional de Medicina.

Art 13. Deixar de esclarecer o paciente sobre as determinantes sociais, ambientais ou profissionais de sua doença.

$\S 3^{\circ}$ Praticar procedimento de procriação medicamente assistida sem que os participantes estejam de inteiro acordo e devidamente esclarecidos sobre o mesmo.

Art 22. Deixar de obter consentimento do paciente ou de seu representante legal após esclarecê-lo sobre o procedimento a ser realizado, salvo em caso de risco iminente de morte.

Art 23. Tratar o ser humano sem civilidade ou consideração, desrespeitar sua dignidade ou discriminálo de qualquer forma ou sob qualquer pretexto.

Art 24. Deixar de garantir ao paciente o exercício do direito de decidir livremente sobre sua pessoa ou seu bem-estar, bem como exercer sua autoridade para limitá-lo.

Art 26. Deixar de respeitar a vontade de qualquer pessoa, considerada capaz fisica e mentalmente, em greve de fome, ou alimentá-la compulsoriamente, devendo cientificá-la das prováveis complicações do jejum prolongado e, na hipótese de risco iminente de morte, tratá-la.

Art 31. Desrespeitar o direito do paciente ou de seu representante legal de decidir livremente sobre a 
execução de práticas diagnósticas ou terapêuticas, salvo em caso de iminente risco de morte.

Art 34. Deixar de informar ao paciente o diagnóstico, o prognóstico, os riscos e os objetivos do tratamento, salvo quando a comunicação direta possa lhe provocar dano, devendo, nesse caso, fazer a comunicação a seu representante legal.

Art 42. Desrespeitar o direito do paciente de decidir livremente sobre método contraceptivo, devendo sempre esclarecê-lo sobre indicação, segurança, reversibilidade e risco de cada método.

Art 44. Deixar de esclarecer o doador, o receptor ou seus representantes legais sobre os riscos decorrentes de exames, intervenções cirúrgicas e outros procedimentos nos casos de transplantes de órgãos.

Art 45. Retirar órgão de doador vivo quando este for juridicamente incapaz, mesmo se houver autorização de seu representante legal, exceto nos casos permitidos e regulamentados em lei.

Art 88. Negar, ao paciente, acesso a seu prontuário, deixar de lhe fornecer cópia quando solicitada, bem como deixar de lhe dar explicações necessárias à sua compreensão, salvo quando ocasionarem riscos ao próprio paciente ou a terceiros.

Art 100. Deixar de obter aprovação de protocolo para a realização de pesquisa em seres humanos, de acordo com a legislação vigente.

Art 101. Deixar de obter do paciente ou de seu representante legal o termo de consentimento livre e esclarecido para a realização de pesquisa envolvendo seres humanos, após as devidas explicações sobre a natureza e as consequências da pesquisa.

Parágrafo único. No caso do sujeito de pesquisa ser menor de idade, além do consentimento de seu representante legal, é necessário seu assentimento livre e esclarecido na medida de sua compreensão.

Art 102. Deixar de utilizar a terapêutica correta, quando seu uso estiver liberado no País.

Parágrafo único. A utilização de terapêutica experimental é permitida quando aceita pelos órgãos competentes e com o consentimento do paciente ou de seu representante legal, adequadamente esclarecidos da situação e das possíveis consequências.

Art 103. Realizar pesquisa em uma comunidade sem antes informá-la e esclarecê-la sobre a natureza da investigação e deixar de atender ao objetivo de proteção à saúde pública, respeitadas as características locais e a legislação pertinente.

Art 110. Praticar a Medicina, no exercício da docência, sem o consentimento do paciente ou de seu representante legal, sem zelar por sua dignidade e privacidade ou discriminando aqueles que negarem o consentimento solicitado.

No atual panorama de leis e regulamentações, tem-se uma maior clareza no conceito do consentimento livre e esclarecido. Ainda que tenham havido significativas mudanças ao longo das décadas anteriores, é no século XXI que os códigos trazem o princípio bioético explicitado em sua forma mais completa, com protocolos bem definidos para os projetos de pesquisa, além de parâmetros que devem ser observados pela comunidade médica ao obter autorização para realizar procedimentos (1).

Destacam-se, em primeiro lugar, os artigos sobre o tema, espalhados por todo Código de Ética Médica, na última versão lançada, em 2010. Além disso, leis próprias para transplante de órgãos, planejamento familiar e reprodução assistida também enfatizam a importância de sempre obter autorização do paciente. Dessa maneira, o novo Código de Ética Médica valoriza sobremaneira a autonomia do paciente, mas impede que esse princípio bioético possa incorrer em exageros, como, por exemplo, o abandono e maior vulnerabilidade do paciente. Nesse sentido, para o entendimento dos legisladores do novo código, a relação médico-paciente deve ser mais cooperativa e simétrica, evitando passar pelos extremos, seja a prática excessivamente paternalista, como outrora, seja no completo desamparo do paciente (27).

Outra norma que possibilitou maior ampliação de sentido e da regulamentação da ideia de consentimento livre e esclarecido foi a publicação da resolução 196 de 1996, da Comissão Nacional de Ética em Pesquisa, por meio da promulgação da resolução $\mathrm{n}^{\mathrm{o}}$ 466/CNS. Essa, que pode ser considerada uma versão atualizada do documento original, de 1996, traz o consentimento esclarecido nas pesquisas de forma ainda mais detalhada. Além disso, reafirmam-se as ideias de capacidade civil do participante de pesquisa, bem como os deveres legais do pesquisador. Destaca-se, também, nessa declaração, um 
maior número de documentos considerados. A primeira resolução utilizava-se do Código de Nuremberg, Declaração Universal de Direitos Humanos e da Declaração de Helsinque, além da Constituição Federal do Brasil. Nesta versão atualizada, foram incluídas a Declaração Universal do Genoma Humano, a Declaração Internacional sobre os Dados Genéticos Humanos e a Declaração Universal Sobre Bioética e Direitos Humanos $(26,28,29)$.

Quadro 7 - Fragmento da Resolução n. 196/96 (26).

\section{IV - PROCESSO DE CONSENTIMENTO LIVRE E ESCLARECIDO}

O respeito devido à dignidade humana exige que toda pesquisa se processe com consentimento livre $\mathrm{e}$ esclarecido dos participantes, indivíduos ou grupos que, por si e/ou por seus representantes legais, manifestem a sua anuência à participação na pesquisa.

Entende-se por Processo de Consentimento Livre e Esclarecido todas as etapas necessárias para que o convidado a participar de uma pesquisa possa se manifestar, de forma autônoma, consciente, livre e esclarecida. Para isso o pesquisador responsável, ou pessoa por ele nomeada, deve:

I. Buscar o melhor momento, condição e locais adequados para que o esclarecimento seja efetuado, considerando para isso as peculiaridades dos convidados a participar da pesquisa, como também a sua privacidade;

II. Prestar informações em linguagem clara e acessível, utilizando-se das estratégias mais apropriadas para a cultura, faixa etária, condição socioeconômica e autonomia dos convidados a participar;

III. Conceder o tempo adequado para que o convidado possa refletir, consultando, se necessário, seus familiares ou outras pessoas que possam ajudá-lo na tomada de decisão livre e esclarecida.

IV. (IV.1) O Processo de Consentimento Livre e Esclarecido para as pesquisas de todas as áreas do conhecimento deverá, ainda, observar os seguintes itens:

a) Apresentar a justificativa, os objetivos e os procedimentos que serão utilizados na pesquisa, incluindo o detalhamento dos métodos a serem utilizados, informando a possibilidade de inclusão em grupo controle ou experimental, quando aplicável;

b) Explicitar os possíveis desconfortos e riscos decorrentes da participação na pesquisa, além dos benefícios esperados dessa participação e apresentar providências e cautelas empregadas para evitar e/ou reduzir efeitos e condições adversas que possam causar dano, considerando características e contexto do participante da pesquisa.

c) Esclarecer a forma de acompanhamento e assistência a que terão direito os participantes de pesquisa, inclusive considerando benefícios e acompanhamentos posteriores ao encerramento e, ou, interrupção da pesquisa;

d) Garantir plena liberdade do participante se recusar a participar ou retirar seu consentimento, em qualquer fase da pesquisa, quando aplicável, sem penalização alguma;

e) Assegurar a manutenção do sigilo e privacidade dos participantes durante todas as fases da pesquisa;

f) Explicitar a garantia de ressarcimento e como serão cobertas as despesas decorrentes da participação dos participantes na pesquisa;

g) Explicitar a garantia de indenização diante de eventuais danos decorrentes da pesquisa;

V. (IV.2) O Processo de Consentimento Livre e Esclarecido das pesquisas na área de ciências da saúde, envolvendo seres humanos, além do previsto no item IV.1, deverá contemplar o seguinte:

a) Explicitar, quando pertinente, os métodos terapêuticos alternativos existentes;

b) Esclarecer, quando pertinente, sobre o método, informando a possibilidade de inclusão em grupo controle ou placebo, explicitando claramente o significado dessa possibilidade;

c) No caso de pesquisas concebidas em âmbito internacional, o pesquisador responsável brasileiro deverá adaptar o Termo de Consentimento Livre e Esclarecido às normativas éticas e à cultura brasileira, utilizando linguagem clara e acessível aos cidadãos comuns, tomando especial cuidado para que se apresente em forma de fácil leitura e compreensão para todos.

VI (VI.3) O Termo de Consentimento Livre e Esclarecido deverá ser:

a) Elaborado pelo pesquisador responsável, expressando o cumprimento de cada uma das solicitações acima. No caso de pesquisas concebidas em âmbito internacional, o pesquisador responsável brasileiro deverá adaptar o Termo de Consentimento Livre e Esclarecido às normativas éticas e à cultura brasileira, utilizando linguagem clara e acessível.

b) Aprovado pelo Comitê de Ética em Pesquisa que referenda a investigação.

c) Rubricado em todas as suas páginas e assinado, ao seu término, pelo voluntário participante da pesquisa ou por seus responsáveis legais e pelo pesquisador responsável, ou seus representantes nomeados, não devendo as páginas de assinaturas constituírem um documento separado. 
d) Elaborado em duas vias, sendo que uma será retida pelo participante da pesquisa ou por seu representante legal e uma arquivada pelo pesquisador. Em ambas constará o endereço e contato dos responsáveis pela pesquisa e do comitê de ética local. Essa garantia deve ser expressa no próprio termo a ser assinado.

VII (IV.4) Nos casos de restrição da liberdade ou do esclarecimento necessários para o adequado consentimento, deve-se, ainda, observar:

a) Em pesquisas envolvendo crianças e adolescentes, portadores de transtorno ou doença mental e participantes em situação de substancial diminuição em suas capacidades de consentimento, deverá haver justificativa clara da escolha dos participantes da pesquisa, especificada no protocolo, aprovada pelo Comitê de Ética em Pesquisa. Nestes casos deverão ser cumpridas as exigências do consentimento livre e esclarecido, por meio dos representantes legais dos referidos participantes, mantendo o direito de informação do convidado, no limite de sua capacidade;

b) A liberdade do consentimento deverá ser particularmente garantida para aqueles participantes que, embora adultos e capazes, estejam expostos a condicionamentos específicos ou à influência de autoridade, caracterizando situações limitadoras da autonomia, especialmente estudantes, militares, empregados, presidiários e internos em centros de readaptação, em casas-abrigo, em asilos, em associações religiosas e semelhantes, assegurando-lhes a inteira liberdade de participar ou não da pesquisa, sem quaisquer represálias;

c) Nos casos em que seja impossível obter o consentimento livre e esclarecido, tal fato deve ser devidamente justificado com explicação das causas da impossibilidade e parecer do Comitê de Ética em Pesquisa;

d) As pesquisas em pessoas com o diagnóstico de morte encefálica deverão atender as seguintes condições:

- documento comprobatório da morte encefálica;

- consentimento explícito ou manifestação antecipada da vontade da pessoa, ou consentimento dos familiares e/ou do representante legal;

- respeito total à dignidade do ser humano;

- inexistência de ônus econômico financeiro adicional à família;

- inexistência de prejuízo para outros pacientes aguardando internação ou tratamento;

- possibilidade de obter conhecimento científico relevante, novo, o qual não possa ser obtido de outra maneira.

e) Em comunidades culturalmente diferenciadas, inclusive indígenas, deve-se contar com a autorização antecipada das autoridades competentes para o início da pesquisa, conforme legislação nacional, bem como da comunidade, por meio dos seus próprios líderes, não se dispensando, porém, esforços no sentido de obtenção do consentimento individual;

f) Quando o mérito da pesquisa depender de alguma restrição de informações aos participantes, tal fato deverá ser devidamente explicitado e justificado pelo pesquisador e submetido ao Comitê de Ética em Pesquisa. Os dados obtidos a partir dos participantes da pesquisa não poderão ser usados para outros fins além dos previstos no protocolo e/ou no consentimento.

\section{Considerações finais}

O Código de Ética Médica, assim como todos os preceitos morais desenhados no desempenho da função médica, desde Hipócrates até hoje, não pode ser deixado em segundo plano, nem mesmo ser desconhecido pelo profissional atuante. É prerrogativa fundamental da habilidade médica o conhecimento dos preceitos que pautam a dignidade, a segurança e o bem-estar do paciente. Eventos como os julgados em Nuremberg ou desastres como os supracitados não ocorrerão se, periodicamente discutirmos os códigos e levarmos uma visão global dos eventos que geraram tais normas.

\section{Agradecimentos}

Este trabalho recebeu apoio financeiro da Fundação CAPES/PNPD através de concessão de bolsa de pesquisa (AAH).

Conflito de Interesses: Os autores declaram não haver conflito de interesses. 


\section{Vittalle - Revista de Ciências da Saúde 29 n. 2 (2017) 116-126}

\section{Referências}

1. Goldim JR. O consentimento informado numa perspectiva além da autonomia. Revista AMRIGS. 2002;46(3,4):109-16.

2. López-Muñoz F, Alamo C, Dudley M, Rubio G, García-García P, Molina JD, et al. Psychiatry and political-institutional abuse from the historical perspective: the ethical lessons of the Nuremberg Trial on their 60th anniversary. Prog Neuropsychopharmacol Biol Psychiatry. 2007;31(4):791-806.

3. Das NK, Sil A. Evolution of Ethics in Clinical Research and Ethics Committee. Indian J Dermatol. 2017;62(4):373-9.

4. Sierra X. [Ethics in medical research in humans: a historical perspective]. Actas Dermosifiliogr. 2011;102(6):395-401.

5. Rice TW. The historical, ethical, and legal background of human-subjects research. Respir Care. 2008;53(10):1325-9.

6. Wecht CH. The history of legal medicine. J Am Acad Psychiatry Law. 2005;33(2):245-51.

7. Entralgo PL. La medicina hipocratica. Madri: Alianza Editorial; 1970.

8. Belkin GS. History and bioethics: the uses of Thomas Percival. Med Humanit Rev. 1998;12(2):39-59.

9. Vollmann J, Winau R. Informed consent in human experimentation before the Nuremberg code. BMJ. 1996;313(7070):1445-9.

10. The Lubeck Disaster. Science. 1930;72(1860):198-9.

11. Seeman MV. Psychiatry in the Nazi era. Can J Psychiatry. 2005;50(4):218-25.

12. Shuster E. The Nuremberg Code: Hippocratic ethics and human rights. Lancet. 1998;351(9107):9747.

13. Grodin MA, Annas GJ. Legacies of Nuremberg. Medical ethics and human rights. JAMA. 1996;276(20):1682-3

14. World Medical Association. Declaration of Geneva. 2013.

15. World Medical Association. Declaration of Helsinki: ethical principles for medical research involving human subjects. J Am Coll Dent. 2014;81(3):14-8.

16. Annas GJ. Globalized clinical trials and informed consent. N Engl J Med. 2009;360(20):2050-3.

17. Okonta PI. Ethics of clinical trials in Nigeria. Niger Med J. 2014;55(3):188-94.

18. Dyer C. Consent needed for organ retention, BMA says. BMJ. 2000;321(7269):1098.

19. Steinbrook R. Protecting research subjects - the crisis at Johns Hopkins. N Engl J Med. 2002;346(9):716-20.

20. Corrigan O. Empty ethics: the problem with informed consent. Sociol Health Illn. 2003;25(7):768-92.

21. Conselho Regional de Medicina do Estado da Guanabara. Ética Médica. Rio de Janeiro. 1974, p. 3-20.

22. Conselho Federal de Medicina. Resolução CFM n. 671/75 1975.

23. Conselho Federal de Medicina. Resolução CFM n. 1081/82. 1982.

24. Conselho Federal de Medicina. Código de Ética Médica. 1984.

25. Conselho Federal de Medicina. Resolução CFM n. 1246/88. 1988.

26. Ministério da Saúde - Conselho Nacional de Saúde. Resolução n. 196/96. 2012.

27. Neves NMBC, de Siqueira JE. A bioética no atual Código de Ética Médica. Revista Bioética. 2010;18(2):439-50.

28. Novoa PCR. O que muda na Ética em Pesquisa no Brasil: resolução 466/12 do Conselho Nacional de Saúde. Einstein. 2014;12(1).

29. Ministério da Saúde - Conselho Nacional de Saúde. Resolução n. 196/96. 1996. 